\title{
RELIGIÓN Y ESPIRITUALIDAD, ¿DOS MODELOS ENFRENTADOS? Trayectorias poscatólicas entre budistas Soka Gakkai
}

\author{
RELIGION AND SPIRITUALITY, TWO OPPOSING MODELS? \\ Post-catholic biographic pathways among Soka Gakkai buddhists
}

\author{
Mónica CoRneJoromejojocps.ucm.es \\ Universidad Complutense de Madrid. España
}

\begin{abstract}
RESUMEN
En el contexto de la privatización de lo religioso aún en curso, muchas biografías religiosas contemporáneas parecen estar motivadas por la búsqueda individualista de una religiosidad alternativa a los repertorios de creencias, rituales e instituciones religiosas tradicionales. Siguiendo el uso creciente de este término por parte de numerosos actores sociales, al menos desde la década de los sesenta del siglo XX, una parte de la Sociología de la Religión se ha referido a esta religiosidad alternativa como "Espiritualidad" (Wood 2009) (Heelas 2008) (McGuire 2008) (Flanagan 2007) (Giordan 2007). Los nuevos modelos de espiritualidad dan cuenta del decaimiento de aquellas formas de religiosidad en las que primaba la comunidad de fe, la participación en la ritualidad colectiva, la membresía como referente identitario. Mientras se abre paso a una atomización, un subjetivismo y relativismo tales, que la reconstitución de una religiosidad colectiva parece imposible, como han sostenido Steve Bruce (1996) o Daniele Hervieu-Leger (2003). Para explorar las posibilidades de este marco teórico se propone aquí el análisis de los discursos y prácticas de conversos budistas que previamente han desarrollado un extenso itinerario espiritual por diversas variedades de la llamada Nueva Era, referente por antonomasia de la fragmentación religiosa y de la revolución subjetiva de lo religioso.
\end{abstract}

\section{Palabras Clave}

Antropología; Budismo; Espiritualidad; Religión; Sociología de la Religión.

\begin{abstract}
In the context of the privatization of religion, still ongoing, many contemporary religious biographies seem to be motivated by the individual search for a religious alternative far away from the repertoires of beliefs, rituals and institutions of traditional religion. Following the increasing use of this term by many social actors at least since the sixties of the twentieth century, part of the Sociology of Religion has referred to the alternative religiosity as Spirituality (Wood 2009) (Heelas 2008) (McGuire 2008) (Flanagan 2007) (Giordan 2007). The new models of spirituality account both for the decay of traditional forms of religiosity (based on the community of faith, the participation in collective rituals and the congregational identity) and for the spreading of a new spiritual subjectivism, whose high individualism have moved some authors to assert that a reconstitution of
\end{abstract}


collective religiosity is impossible, as Steve Bruce (1996) and Daniele Hervieu-Leger (2003) have argued. This paper tries to explore the possibilities of this theoretical framework analyzing some discourses, discourses and practices of Buddhist converts in Spain, who have previously developed an extensive spiritual ride through several varieties of the so-called New Age milieu, the most important style of religious fragmentation and subjective revolution in the religious fields.

\section{KEYWORDS}

Spirituality; Religion; Buddhism; Anthropology; Sociology of Religion.

\section{INTRODUCCIÓN}

En el contexto de la privatización de lo religioso, aún en curso, muchas biografías religiosas contemporáneas parecen estar motivadas por la búsqueda individualista de una religiosidad alternativa a los repertorios tradicionales de creencias, ritos e instituciones religiosas. La Sociología y la Antropología de la Religión se han referido a esta religiosidad alternativa como Espiritualidad (Wood 2009) (Heelas 2008) (McGuire 2008) (Flanagan 2007) (Giordan 2007) (Forman 2004) (Roof 2003). Siguiendo el uso creciente de este término por parte de numerosos actores sociales desde la década de los sesenta del siglo XX, la noción de espiritualidad no se refiere ya a la mística tradicional (Forman 2004:45 y ss.). Según Paul Heelas, uno de los sociólogos más relevantes en el desarrollo de esta tendencia, lo que él llama Spiritualities of Life abarca un conjunto desigual de creencias y prácticas compuesto por las corrientes Nueva Era, Neopaganismo y Nuevos Movimientos Religiosos. Todos ellos tendrían en común tanto el énfasis en la noción de "espíritu", "espiritualidad", etc. como un rechazo a los dos modelos dominantes de religión tradicional (Heelas 2008:110). En este panorama, el crecimiento de las prácticas asociadas a nuevos modelos de espiritualidad habría puesto de manifiesto, además, la opción de muchos actores sociales por formas de religiosidad en las que la comunidad de fe, la participación en la ritualidad colectiva, la membresía como referente identitario pierden importancia y dan paso a una atomización, subjetivismo y relativismo tales, que la reconstitución de una religiosidad colectiva parece imposible, como han sostenido Steve Bruce (1996) o Daniele Hervieu-Leger (2003). Otros, como Beck (2009), Heelas (2008) o Tacey (2004), han sostenido que la clave de este cambio y las posibilidades de reconstitución colectiva de la esfera religiosa está en una transformación general en las relaciones de poder en las que individuo y comunidad reformulan sus vínculos.

Hasta ahora, una de las características de esta transformación en España es su relativa invisibilidad pública. La práctica ausencia de información estadística sobre prácticas, consumos 0 creencias de la New Age se explica en parte por el hecho, confirmado por trabajos de campo (Griera y Urgel 2002), de que un buen número de estas prácticas están relacionadas con actividades económicas irregulares.

Como ha señalado Martin Baumann (2002:92), después de las tradiciones zen, el budismo que ha crecido con mayor rapidez en Europa es el budismo Nichirén de Soka 
Gakkai. Este y otros budismos se han incorporado en Europa como otras alternativas más en el vasto repertorio de la Revolución Espiritual, y en este sentido, Soka Gakkai España constituye un buen referente de estudio para la sociología de la espiritualidad, pero también presenta paradojas que ponen límite tanto a los presupuestos teóricos como a los usos conceptuales de este enfoque, especialmente por lo que se refiere a la dicotomía entre las nociones de "religión" y "espiritualidad" como claves para interpretar el cambio religioso contemporáneo. Este trabajo tiene por objetivo precisamente explorar y discutir las posibilidades y límites empíricos de este marco teórico a partir de un estudio de caso de los conversos budistas de Soka Gakkai en Madrid. Dada la ausencia de fuentes estadísticas también sobre este grupo en España (Díez de Velasco 2009), la investigación se ha desarrollado a partir de trabajo de campo etnográfico, incluyendo un periodo de observación participante de tres meses durante el que se ha participado en las sesiones de los "grupos de diálogo" de Soka Gakkai en Madrid. También se han realizado entrevistas a doce miembros del grupo (nueve mujeres, tres hombres) y se han tenido en cuenta las conversaciones informales habidas con estos, con otros miembros y con familiares y amigos no budistas próximos a ellos. En este proceso ha salido a la luz la importancia de los itinerarios espirituales previos a la conversión para explicar unas prácticas entre cuyas características se encuentra la permanente transformación y un cierto nomadismo religioso. Teniendo en cuenta esto, la discusión teórica partirá de una breve presentación de la dicotomía conceptual entre "espiritualidad" y "religión" a través de los trabajos de Paul Heelas y Linda Woodhead, que tienen como particular ventaja aquí el hecho de estar basados en estudios de caso con un enfoque metodológico similar. A continuación, se expondrán los resultados de la investigación a partir de los discursos y descripción de las prácticas de los budistas Nichiren que residen y practican en Madrid. En tercer lugar, se revisarán las hipótesis sobre el poder del individuo y la restauración de la institución religiosa analizando la estructura de decisiones activada en las trayectorias espirituales, y finalmente se concluirá sobre algunas hipótesis.

\section{Espiritualidad fRente a Religión: la tRANSFORMACIÓN de lO SAGRAdO COMO DESPLAZAMIENTO DE LA AUTORIDAD}

En la línea general de las tesis sobre "la religión invisible", Heelas y Woodhead (2003:145; 2008:9) han sostenido que la transformación contemporánea de las formas religiosas consiste en una desintegración de las formas institucionales de la creencia y el ritual así como su posterior reinvención en torno a estructuras organizativas más o menos novedosas. Estas estructuras organizativas se refieren en primer lugar a los aspectos puramente institucionales, esto es, al progresivo declive de las instituciones eclesiales o congregacionales y su sustitución actual por la difusa y dispersa red de asociaciones, centros de meditación, cursos sobre todo tipo de técnicas y conocimientos esotéricos, tiendas, servicios profesionales, etc. Paul Heelas y Linda Woodhead han descrito 
elocuentemente el contraste entre estos dos paisajes organizativos con los pares semánticos dominio/ambiente/congregación/holismo. Según estas etiquetas, las iglesias ("dominio congregacional") conforman un campo religioso en el que las instituciones guardan entre sí relaciones paradigmáticas de modo que la adscripción religiosa implica una exclusión de otras adscripciones (en el sentido de que el metodista no es anglicano, el católico no es baptista, etc.). Este es el paisaje del modelo "life-as" de religiosidad, en el que la identidad religiosa y social guardaba cierto paralelismo. Pero este se va sustituyendo por un fragmentario y fuertemente subjetivo "ambiente holístico" que emerge como modelo "subjective-life" de religiosidad. En este, y a diferencia del campo religioso tradicional, un desigual agregado de especialistas profesionales, asociaciones de actividades diversas, escuelas esotéricas, grupos de ayuda, etc. guardan entre sí relaciones característicamente sintagmáticas en las que un individuo puede participar en organizaciones y actividades muy diferentes al mismo tiempo, sin que ello implique nada respecto a adscripción social alguna.

Semejante revolución del paisaje organizativo de lo sagrado puede leerse con provecho en los términos de un cambio respecto a los lugares culturales de la autoridad, esto es, como un desplazamiento de la fuente que sanciona la legitimidad del conocimiento y la práctica religiosos. Siguiendo a Charles Taylor, Heelas y Woodhead describen las diferencias entre religión y espiritualidad como una oposición entre la autoridad externa (colectiva, moral, institucional, simbólica) y la interna o propia (individual, vivida, subjetiva, sensitiva). La autoridad externa es la propia de una religiosidad asumida desde la identidad social del life-as model, que se refiere tanto a los roles establecidos para los individuos en función de sus posiciones en un sistema social y religioso, como a la condición de miembro de una iglesia. La religiosidad colectiva, en la que el grupo o los especialistas reconocidos por el grupo son la fuente de validación del conocimiento y la experiencia religiosa (Hervieu-Leger 2003), se contrapone así a la religiosidad individual, en la que la experiencia de cada individuo emerge como espacio legítimo de la autoridad religiosa. En este sentido, el modelo que llaman congregacional se caracteriza por una actitud de adhesión a una verdad externa, habitualmente compuesta de un repertorio de creencias gestionado por la institución o la sociedad y sus especialistas tradicionales, mientras que el modelo que llaman individualista se desarrolla en la exploración y expresión de la verdad sobre uno mismo y para uno mismo, una verdad centrada en el propio proceso de exploración y su expresión personal. Como aparece en numerosos estudios, es un discurso frecuente entre los actores sociales de la Nueva Era y otras Spiritualities of Life atribuir a la religión, la tradición y las iglesias un carácter represivo, limitante de la expresión individual por su regulación ideológica sobre las creencias, al tiempo que se atribuye a las nuevas espiritualidades un carácter abierto y holístico que favorece el cultivo de lo personal y la integración de diferentes fuentes de experiencia y de conocimiento.

Pero la Revolución Espiritual Subjetiva de la que habla Heelas no se limita al paisaje institucional de lo sagrado. La dicotomía lo es también, por tanto, entre creencias y experiencias, entre doctrina externamente producida (e internamente reproducida), 
y búsqueda personal en el interior de las propias emociones acerca de la validez de las verdades disponibles. Así, el nacimiento del llamado Paradigma de la Espiritualidad (Wood 2009) también trae consigo un profundo proceso de reorganización en el propio conocimiento religioso, sea doctrinal o práctico. En una forma nueva de sincretismo, los practicantes de la nueva espiritualidad fungen de inquietos bricoleurs, que no solo buscan sino que fundamentalmente construyen su propio conocimiento religioso al estilo de un "patchwork belief", como elocuentemente lo ha denominado Daniele Hervieu-Leger (2003:165). Así, a diferencia de otros sincretismos religiosos de carácter más típicamente colectivo, esta libertad creativa de la nueva espiritualidad enfatiza el papel de cada individuo como centro de la vivencia religiosa y como autoridad última de su conocimiento espiritual, en convergencia con otras tendencias de subjetivización en otras esferas de la experiencia social, como han propuesto desde Charles Taylor (1992) a Richard Sennet (1998).

En este sentido, Heelas y Woddhead relacionan su subjective-life model con el declive de la familia basada en roles y la creciente preferencia por relaciones familiares emotivas en las que se valora la expresión individual sobre el rol. Igualmente, la espiritualidad holística contemporánea se relaciona con una mayor atención al bienestar físico y emocional y la preocupación por el cuidado terapéutico "integral", siendo abiertamente crítica con la bio-medicina. Pero sin duda, la mayoría de transformaciones sociales de las que la nueva espiritualidad es una expresión guardan relación explícita con la cuestión del poder. Así, tanto los ámbitos del trabajo como la educación, según Heelas y Woodhead, han dejado atrás las estructuras rígidas y jerárquicas de relaciones entre sus actores sociales para dar paso a relaciones fluidas, descentralizadas, en las que trabajadores y niños son animados a buscar su propio desarrollo personal. La enseñanza basada en el conocimiento de una materia deja paso al modelo de competencias. El trabajo basado en la especialización funcional deja paso al aprendizaje continuo y la flexibilidad. Y al mismo tiempo los grupos políticos y los sindicatos pierden importancia, la pertenencia a una comunidad local o a un grupo específico pierden valor, y van ganando espacio social las asociaciones voluntaristas así como un modo de relación en red que permite al individuo interactuar con diversos grupos y expresar su pluralidad subjetiva. Desde un punto de vista moral, estas transformaciones pueden ser vistas también como la transición desde la ética del Bien Común hacia la ética de la subjetividad, en la que una pregunta antes banal cobra ahora una autoridad y centralidad inusitadas: la cuestión de "¿cómo te hace sentir esto?". Y es que la espiritualidad contemporánea tal vez debe menos a las tradiciones místicas que a la expansión del concepto de "bienestar". Y esta es, en parte, la Revolución Humana que propone Soka Gakkai: menos togas y retiros espirituales, y más felicidad global (Ikeda 1999; 2008). 


\section{EL BUDISMO LAICISTA COMO DESAFÍO CONTEMPORÁNEO}

Uno de los fenómenos más interesantes en el marco de la Revolución Espiritual Subjetiva es el caso del budismo Nichiren. Este budismo se fundamenta en las enseñanzas del monje japonés del siglo XIII Nichiren Daishonin, y tiene dos ramas principales que emergen en el Japón del siglo XX: el movimiento Risho Koseikai, y el más extendido Sokka Gakkai o Sociedad de los Valores, fundado por Tsunesaburo Makiguchi en 1930 (Wilson y otros 2000). Aunque la clasificación analítica del budismo del lado de la categoría "religión" pueda ser más o menos problemática, la importancia de este budismo en el debate sobre religión y espiritualidad descansa en el hecho de que los propios miembros de Soka Gakkai de España viven y reivindican su práctica como un ejemplo de espiritualidad en el sentido de la Revolución Espiritual.

\section{Espiritualidad frente a Religión: algunos discursos}

Entre los miembros de Soka Gakkai de España se comparten y se reproducen ampliamente esas representaciones dicotómicas de la Sociología de la Espiritualidad en las que "la religión" comparece como una rígida estructura de poder externo ilegítimo que se opone a la espiritualidad individual y libertaria que consideran característica del budismo Nichiren. Así, en palabras de Rocío (27 años):

Lo que más me gusta de este budismo es... que no hay nadie que te obligue a nada, eres libre, totalmente libre, puedes hacer lo que quieras, si quieres ir a la reunión vas, si no quieres no vas, y nadie te dice... jeh, tú no has venido! ¿Eh? porque... si no vienes... ¿¿quée!

También Chiara (34 años) cuenta de su infancia que:

...durante muchos años siempre era como que tienes que ser buena porque, si no, vas al infierno, tienes que obedecer y no sé qué y yo me he criado en una guardería de monjas también... y había una sor Antonella que era tela. En la primera comunión ella siempre me gritaba, yo era siempre la oveja negra, no sé, así que nunca me he tomado muy en serio la... religión, no estaba conectada ahí..

Frente a esa memoria de lo religioso, que en Soka Gakkai de España procede habitualmente de una enculturación religiosa católica, la experiencia de la práctica budista se presenta a sí misma como una espiritualidad no solo emancipadora, sino también extraordinariamente pragmática, como se aprecia en este testimonio de los primeros días de otra practicante (Antonella, 36 años):

Mucha gente se asusta al ver directamente como es la práctica con más gente, que se parece mucho a la iglesia católica también, dicen... con lo de discípulo-maestro... todas esas cosas me hubieran asustado directamente desde el principio, pero Violeta no empezó por ahí. Ella 
dijo: haz solamente la práctica y mira lo que pasa... y nada, y empecé a invocar así todos los días, pero en plan a lo tonto, y ella me dijo intenta ponerte unas metas para que veas que funciona, unas metas para qué invocar... y puse 2 o 3 que eran muy difíciles y de repente llegué ahí; -¿Cuáles eran?; -Bueno, primero pedí... en plan... aclararme un poco con mi pareja, si la tenía que dejar o no, soltar o no, porque ya... y poco tiempo después conocí a otra persona. $Y$ también pedí tener un contacto y un pedido con $K$, que es un cliente muy gordo, casi imposible... - ¿Lo pediste con daimoku'? ${ }^{1}$-Lo pedí con daimoku y ni en una semana contactamos y bueno, y ya, tuve el pedido y todo 2 .

En esta narración se aprecia el uso del budismo Nichiren como herramienta de empoderamiento personal, mientras que, por lo que respecta a la experiencia de la religión católica se critica la pasividad, la dependencia de un poder externo. Así lo expresa Michela (32 años):

Para mí fue muy impactante cuando enfermó mi padre, de un tumor en la cabeza... de repente todo el mundo empezó a rezar... ahora entiendo por qué pero entonces... me daba tanta rabia... y estuvimos en una iglesia, mi madre y yo, y me sentía... no me sentía conectada... todo el mundo estaba rezando a algo pero jnadie estaba pensando en la fuerza de mi padre! [...] Cuando mi padre salió del quirófano, mi madre: jay! ¡Doy las gracias a san Antonio! ¡Papá se ha salvado solamente por san Antonio!, y yo: ¡que no mamá! ¡Que lo ha salvado el médico y es por la fuerza de papá! [...] Yo dejé de creer en el catolicismo porque me molestó muchísimo que todas las energías de la gente se fueran para afuera y no hacia la persona... la fuerza es cada persona...

Ciertamente, estos discursos se producen entre conversos cuya categoría "religión" es casi sinónimo de Iglesia Católica, pero son coherentes con la representación general de la religión en el marco de la Revolución Espiritual de la que hablan Heelas y Woodhead. Sin embargo, la observación participante de la práctica cotidiana en el budismo laico también deja ver que esta liberadora práctica, que hace al individuo más poderoso y más autónomo, no solo en su dimensión espiritual sino también en otros aspectos de la vida, se desarrolla en el seno de una comunidad jerarquizada de practicantes, en la que el grupo vecinal o el magisterio del presidente lkeda son elementos imprescindibles para comprender el funcionamiento y el significado pleno de la práctica. Pero ¿qué es Soka Gakkai? Y ¿en qué consiste la religiosidad de sus practicantes en España?

\footnotetext{
${ }^{1}$ Daimoku es el nombre que recibe el mantra que los budistas nichiren cantan.

${ }^{2}$ La entrevistada ha pedido expresamente que anotemos su disconformidad con su propia expresión original "pedir con daimoku", propia de sus primeros días como budista, y en la actualidad sustituida en su vocabulario habitual con "invocar". En su razonamiento actual sobre estos términos aduce que "pedir" significa confiar en una agencia externa ("pedir algo a alguien") mientras que "invocar" significa "abrir los ojos del Buda" interior, confiar en su propia agencia, por tanto.
} 


\section{Soka Gakkai. La práctica y la organización en España}

En primer lugar, y como muchos de sus miembros afirman una y otra vez, Soka Gakkai es Nam Myoho Renge Kyo. Este mantra en japonés recibe el nombre de daimoku y su recitación es la práctica principal del budismo Nichiren. La reforma de Nichiren Daishonin defendía que el Sutra del Loto contiene lo esencial de las enseñanzas del Buda Sakyamuni y esta fórmula (cuyo significado literal es "Devoción al Sutra del Loto de la Ley Sublime") es diariamente recitada por los seguidores de Sokka Gakkai frente al Gohonzon. El Gohonzon es una representación en papel del propio mantra y nombres significativos del Sutra del Loto (príncipes, reyes y boddhisatvas), escritos en grafía japonesa. Esta lámina se considera un mandala y se guarda en un pequeño armario (butsudan). Frente al Gohonzon, con las palmas de las manos unidas y un pequeño rosario de cuentas en ellas, se recitan tanto el daimoku como el gongyo. Cantar o "hacer gongyo" consiste en recitar unos fragmentos del Sutra del Loto en japonés escogidos por Nichiren Daishonin ${ }^{3}$ e idealmente cada practicante debe hacer gongyo por la mañana y por la noche, aunque en conversaciones informales es frecuente escuchar que los practicantes no siempre lo hacen, normalmente por estar cansados o muy ocupados.

Daimoku y gongyo se recitan a solas y en grupo. Cada mes, los grupos de base de Soka Gakkai se reúnen formalmente. Se trata de reuniones vecinales que reciben el nombre de zadankai y se celebran habitualmente en el domicilio del que haya sido nombrado responsable de la zona. Además de recitar, el zadankai es un espacio para el encuentro y la puesta en común de las reflexiones y experiencias cotidianas. En las sesiones en las que he participado, cada reunión tomaba un tema de reflexión propuesto por los responsables del grupo y un par de personas se han preparado una lectura de introducción al tema extraída de la revista mensual de la organización en España, Civilización Global. La estructura de cada reunión es repetitiva. Los participantes se reúnen sentados frente al Gohonzon de la casa y todo empieza haciendo daimoku y gongyo. Después de recitar, las personas encargadas ese mes de preparar la lectura introducen el tema y exponen sus reflexiones. En las tres reuniones de diálogo mensual a las que he tenido oportunidad de asistir (así como en otras cinco reuniones convocadas con otros motivos), las lecturas propuestas se han centrado muy especialmente en frases del presidente actual de Soka Gakkai, sensei Daisaku Ikeda, que cada mes ofrece sus reflexiones en las revistas y libros de la organización. Al hilo de la lectura escogida, los que hablaban iban poniendo el tema en relación con alguna experiencia personal reciente haciendo hincapié en la actualidad y en la importancia cotidiana de las palabras del presidente Daisaku Ikeda. Después de este momento, los demás participantes eran invitados a exponer sus reflexiones, sus dudas, sus experiencias. Al dar por finalizada la reflexión colectiva siempre se recitaron tres daimoku frente al Gohonzon y se dio las

${ }^{3}$ Concretamente se recitan los capítulos 2 ("Medios hábiles") y 16 ("Duración de la vida de El-que-asillega") del Sutra del Loto. 
gracias al Gohonzon y a los participantes. En todas las reuniones a las que he asistido, tanto de diálogo mensual como otras, el anfitrión ofreció a sus invitados algo de comer antes de irse.

Además de este tipo de reunión, Soka Gakkai celebra a menudo reuniones abiertas en las que son invitados a participar amigos y familiares de los miembros de la organización. En España lo habitual es ser invitado por un miembro de Soka Gakkai a los encuentros abiertos que se celebran en los kaikan, los centros de reunión. En el periodo en que se ha desarrollado esta investigación el primer kaikan de Madrid se había cerrado para construir uno nuevo, y las cuatro reuniones a las que asistí fueron celebradas en domicilios particulares. El nuevo kaikan, sede central de Soka Gakkai España se ubica actualmente en Rivas-Vaciamadrid y empieza a funcionar desde octubre de 2011. Sin embargo, a pesar de la importancia del kaikan para ciertas actividades colectivas, las reuniones vecinales domésticas eran y siguen siendo la base social para el conjunto de la organización.

En los diferentes países en que la Sociedad de los Valores tiene presencia, la estructura de la organización depende de la combinación entre la distribución territorial de los domicilios de sus miembros y la organización territorial específica de los Estados en sus distintos niveles. Esto hace que cada país, con una membresía numéricamente distinta y con una organización territorial diferente, presente especificidades. En el momento de esta investigación, y de acuerdo a la información suministrada por la encargada de relaciones públicas de la organización en entrevista (30 junio 2010), Soka Gakkai España se divide en siete grandes regiones que incluyen diferentes Comunidades Autónomas ${ }^{4}$ en las que se reparten aproximadamente 5000 practicantes del budismo Nichiren ${ }^{5}$. Cada región se divide en zonas, dependiendo del número de miembros. Cada zona se divide a su vez en distritos generales y cada distrito general se compone de dos o de tres distritos. En cada distrito se organizan los diferentes grupos de diálogo (zadankai), que están compuestos idealmente de unas diez personas que viven próximas entre sí. Al frente de cada nivel existe un "responsable" que cumple funciones de coordinación y organización.

En varias ocasiones, tanto en entrevistas como en reuniones de diálogo abiertas a familiares y amigos, los responsables de diferentes niveles ponen cuidado en insistir sobre la idea de que los responsables de grupo, distrito, o zona no tienen capacidad de tomar decisiones por sus representados. Como señala Inés Vázquez, responsable de

\footnotetext{
${ }^{4}$ Sur: Andalucía y Murcia; Canarias. Centro: Madrid, Castilla-La Mancha, Castilla León (Salamanca). Noroeste: Galicia, León, Asturias. Norte: País Vasco, La Rioja, Navarra, Cantabria. Noreste: Cataluña, Aragón. Levante: Valencia.

${ }^{5} \mathrm{En}$ el caso de la región centro, esta se divide en 5 zonas que son: Madrid norte, Madrid sur, Madrid histórico, Madrid castellana y Madrid este. No existen datos estadísticos sobre la membresía en España. Esta información procede de la responsable de relaciones públicas de Soka Gakkai España e incluye no solo a miembros estables de la organización sino también a los simpatizantes que frecuentan las reuniones abiertas, así como a las familias de los miembros activos.
} 
relaciones públicas, la tarea de estos responsables es "convocar y organizar" eventos, así como "velar por la felicidad de las personas de su grupo" y también "alentar, acompañar". De hecho, esta función de acompañamiento justifica la división de género y edades que atraviesa a toda la organización. Así, lo ideal es que en cada grupo existan cuatro responsables: una de mujeres, otra de chichas jóvenes, un responsable de hombres y otro de chicos jóvenes, cada uno de los cuales se espera que sea capaz de establecer una relación cercana con sus semejantes en género y edad dentro del grupo.

A estos grupos organizados territorialmente se les añaden "departamentos" o "divisiones". Las secciones nacionales de chicos, chicas, mujeres y hombres se consideran departamentos en este sentido y tienen cuatro responsables de nivel estatal. La diferenciación por edad no es estricta. Se considera parte de los grupos de jóvenes a los chicos y chicas solteros y sin hijos hasta los cuarenta años aproximadamente. Aunque la sección infantil no es exactamente un departamento como los otros, también hay un responsable que organiza actividades para el llamado Grupo Futuro, formado por los hijos de los miembros. Así también, en España hay dos divisiones profesionales de reciente formación, una de artistas y otra de educadores. Por encima de toda esta estructura está la Presidencia que tiene funciones de representación y organización pero tampoco tiene funciones de mando exactamente. Las funciones de mando y toma de decisiones las tiene el Comité Ejecutivo formado por los responsables de región, los responsables estatales de secciones y el presidente. Y aún al lado de la Presidencia (o "debajo" de toda la organización según las palabras de sus miembros) existen dos grupos de jóvenes (Byakuren de chicas y Sokahan de chicos) dedicados a "la protección de los miembros", objetivo que se concreta en las actividades de apoyo logístico a los eventos colectivos. Estas personas son una parte fundamental pero "invisible" de la organización y sus labores consisten tanto en recibir a los invitados como en disponer el espacio, la comida, 0 cantar daimoku para favorecer el buen desarrollo de las reuniones.

Como se puede apreciar, el desarrollo institucional de una organización pequeña como la española está notablemente estructurado. Además, no deja de ser significativo que por encima de esta de Soka Gakkai España se encuentra SGI, Soka Gakkai Internacional con sede en Japón, que articula las diferentes organizaciones estatales y continentales, así como numerosas organizaciones paralelas de la Sociedad de los Valores, como universidades, museos, fundaciones, editoriales, etc. No obstante, lo sustantivo para el estudio de esta práctica tal y como se da en España es que con esta descripción se pueda apreciar que este budismo que sus miembros viven y presentan como una espiritualidad altamente individualizada y emancipadora de las rígidas estructuras del cristianismo, puede ser clasificado plenamente del lado de las prácticas "religiosas" en el sentido que la Sociología de la Espiritualidad da al adjetivo. De hecho, Karel Dobbelaere (2000:238) ha defendido la hipótesis de que Soka Gakkai se comporta como una característica "organización-pilar" a imagen y semejanza de las estructuras congregacionales de los campos religiosos centro-europeos en los años 50 del siglo XX, en el seno de las cuales sus miembros encontraban una variedad amplia de actividades y servicios seculares (incluyendo partidos políticos) para desarrollar una vida más o menos autár- 
quica, segregada del resto de la sociedad secular y centrada en la red social del grupo religioso. Así pues, y como se planteaba anteriormente ¿cómo se articula la vivencia de este budismo como una práctica altamente individualizada en el seno de una organización fuertemente estructurada, jerárquica y con una clara división de género?

\section{LA ARTICULACIÓN DE LAS VARIEDADES RELIGIOSAS CONTEMPORÁNEAS}

A pesar del notable desarrollo institucional de la organización, el fundamento de toda la estructura de Soka Gakkai descansa en tres pilares más propios de la Revolución Espiritual: una doctrina inmanentista, una sencilla práctica orientada al empoderamiento individual y antecedentes en otras prácticas y doctrinas aprendidas a lo largo de las búsquedas personales en pos de la espiritualidad.

\section{Manifestar la budeidad}

Como hemos visto, una de las referencias recurrentes en los discursos del bricoleur espiritual es la alta valoración de los itinerarios espirituales como vías al empoderamiento individual y la mejora de la vida personal como consecuencia de ello. En el caso de los budistas nichiren, la primera vez que alguien "recibe la ley" (recibe la primera noticia sobre Nam Myoho Renge Kyo) es invitado a comprobar la eficacia utilitaria de cantar daimoku invocando por alguna cosa concreta que el principiante desea para sí mismo, y esperando el cumplimiento de este deseo como resultado práctico de la recitación. Esto recibe el nombre de "determinar", es decir, definir metas, objetivos personales; y aprender a determinar es una de las herramientas con mayor eficacia cognitiva en el proceso de empoderamiento individual, en la medida en que obliga al practicante a concretar y objetivar sus deseos personales. En este sentido, se asume que el poder de cantar daimoku se localiza en "el corazón de la persona" que practica habitualmente, y que descubre su budeidad a través de la práctica. "Manifestar la budeidad" significa también visibilizarse uno mismo, "salir hacia afuera", sacar a la luz el yo personal de forma completa y sin timidez. A menudo se dice que el Gohonzon es un espejo de quien recita ante él, y por ello el mandala tiene un poder desvelador que al mismo tiempo ejerce de imperativo: el imperativo de "conectarte contigo mismo", de adoptar un hábito de honestidad íntima que ha de traer como consecuencia una mayor coherencia en la conducta personal, tanto en el sentido netamente moral de "ser la mejor versión de uno mismo", como en el sentido utilitarista de "conseguir más cosas" (ganancias instrumentales extraordinariamente concretas como el ascenso social, la mejora económica y laboral, o las mejoras del estado físico y emocional).

Al mismo tiempo que la práctica se orienta hacia esta ética centrada en el individuo y sus necesidades concretas inmediatas, el budista nichiren fundamenta su creencia en la doctrina del Dharma en el Sutra del Loto según Nichiren Daishonin, y en la lectura actual del Sutra y de los textos originales de Nichirén (Gosho) según Daisaku Ikeda. 
Como se decía anteriormente, Nam Myoho Rengue Kyo significa "Devoción al Sutra del Loto de la Ley Sublime". Esa Ley que es Dharma alude a la sutil realidad que subyace a toda manifestación, dándole su materia y su forma. Así, tanto el yo como el mundo, los deseos propios o las circunstancias vitales, son manifestaciones de esa realidad esencial permanente. Este carácter permanente y esencial del omnímodo Dharma le da su carácter de ley, y especialmente en el sentido que más habitualmente se encuentra referido entre los budistas nichiren, como ley de la simultaneidad de causa y efecto. Mientras que la noción de Karma alude a la sucesión temporal, Dharma alude a la simultaneidad omnímoda de lo real. Esto fundamenta la práctica del daimoku en la medida en que recitación del mantra equivale a una suerte de "sintonización" y "sincronización" del individuo (y sus objetivos personales) con ese Dharma Sublime. Así, el mantra es la herramienta que permite al individuo conseguir sus objetivos (efecto) invocando por sus determinaciones (causa). En cierto modo, puede decirse, que la convergencia entre doctrina y práctica conducen a una sacralización simultánea del individuo y las herramientas espirituales. Sin embargo, para la mayoría de conversos de Soka Gakkai aquel "conseguir más cosas" fortaleciendo la individualidad por medios espirituales es el fruto de un laborioso aprendizaje anterior.

\section{Aprender el self: notas sobre género}

Como se puede apreciar, algunas de las expresiones de los budistas nichiren que se recogen aquí para describir la eficacia del daimoku recuerdan mucho a algunas de las más populares teorías de la Nueva Era como la ley de la atracción de Louise L. Hay, la teoría de las Sincronicidades de James Redfield, o las visualizaciones de Deepak Chopra. De hecho, la práctica asidua de las Afirmaciones de Louise L. Hay es considerada por muchas de las mujeres que practican el budismo Nichiren en España como antecedente personal de su preparación para aceptar el poder del daimoku, como en ocasiones he podido escuchar en las reuniones de diálogo. En las entrevistas y reuniones con hombres, sin embargo, las prácticas anteriores al budismo Nichiren no se refieren tanto a rituales del esoterismo contemporáneo como al estudio y lectura de textos de otros budismos y otros 6 . Aunque los hombres y mujeres entrevistados comparten en

\footnotetext{
${ }^{6}$ Merece señalarse que la mayor parte del trabajo de campo se ha realizado entre mujeres, encontrando dificultades serias para participar en las reuniones exclusivamente masculinas. Así también, es relevante señalar que según la responsable de relaciones públicas de Soka Gakkai, así como por el testimonio de jóvenes byakuren, los hombres de la organización son algo menos de la mitad de mujeres en el total de la membresía. A falta de datos estadísticos, podemos tomar como orientación los datos de Italia, donde la ratio hombre-mujer es de 4/8 según Macioti (2000)]. A pesar de ello, se ha participado en reuniones mixtas y realizado entrevistas a tres hombres. La representatividad de la muestra es claramente débil, si bien es cierto que el contraste es lo suficientemente claro en cuanto a la total ausencia de determinados testimonios entre las mujeres que se han conocido durante la investigación (aproximadamente 40 , con diferente grado de interacción). En este sentido, ciertamente, estas notas sobre género no pueden ser concluyentes en cuanto
} 
general algunos elementos socio-biográficos clave como: una enculturación católica, profesiones liberales, conocimiento de disciplinas holísticas y esotéricas, o incluso el hecho de que una inmensa mayoría ha "recibido la Ley" de una mujer, las diferencias en el discurso sobre sus propias creencias representan la herencia de trayectorias espirituales algo distintas. En concreto, los hombres entrevistados han perseguido su espiritualidad especialmente a través del estudio y las lecturas, mientras que las mujeres han perseguido la espiritualidad a través de la integración del estudio, la experimentación práctica y la participación activa en redes de servicios propios del "ambiente holístico". En ambos casos estamos ante un modelo de conversión activa y procesual (Vallverdú 1999; Lofland 1965) desde la primera socialización religiosa en el seno de la familia, hasta recibir el Gohonzon, mediando entre ambos puntos no tanto una experiencia dramática de conversión fulgurante como sucesivas etapas intermedias. Contempladas desde la actualidad, para los budistas nichiren de España estas etapas intermedias constituyen un aprendizaje y un disciplinamiento cognitivo y ético (tanto en sentido conductual como normativo) que hoy encuentra su mejor expresión en el daimoku y en Soka Gakkai. Sin embargo, la preparación para "manifestar la budeidad" no parece la misma para hombres y mujeres. Son fundamentalmente las mujeres y chicas de Soka Gakkai de España las que han construido su biografía espiritual mediante la incorporación de un esquema cognitivo que aísla el self como autoridad, hasta sacralizarlo en el budismo.

Estas diferencias coinciden en parte con las tesis de Woodhead sobre la Revolución Espiritual como feminización de lo sagrado (Heelas 2008; Woodhead 2007) pero no completamente. Para Woodhead la alta tasa de feminidad del "ambiente holístico" se explica también por la autonomía y la legitimidad que la espiritualidad subjetiva da a la expresión personal y a la afirmación de la individualidad de las mujeres. Sin embargo, también establece una diferencia de género entre una espiritualidad relacional, abierta hacia los demás y propia de las mujeres, y una espiritualidad utilitaria estrictamente centrada en uno mismo, como algo propio de hombres. Entre los practicantes del budismo Nichiren de España no se ha encontrado que tal diferencia tenga un perfil de género, principalmente porque el sentido utilitarista de "conseguir más cosas" y el individualismo de "manifestar la budeidad" (clasificados por Woodhead como masculinos) son valores activos para todas las mujeres y son, de hecho, un tema recurrente en los testimonios de los grupos de diálogo femeninos. Y al mismo tiempo, Soka Gakkai también se caracteriza por los valores relacionales de la Revolución Humana como proyecto para la felicidad colectiva, y hasta donde ha sido posible conocer la opinión de los miembros masculinos de la organización, esto es algo compartido por todos aunque no es tan recurrente como el énfasis en la individualidad en las reuniones femeninas, estando algo más presente en las mixtas. No obstante, esto sería indicador precisamente de las ventajas de la práctica budista para las mujeres como herramienta para expresar su subjetividad.

a los varones, pero sí pueden ser generalizables a las mujeres. 
En cualquier caso, los itinerarios espirituales de hombres y mujeres, con sus diferencias, pueden contemplarse también desde sus paralelismos y en ellos encontramos un interesante esquema de comportamiento generalizado en el discurso. Como en otros testimonios de conversión, todo comienza con un desengaño espiritual. La mayoría de los miembros de Soka Gakkai de España aprendieron la doctrina y las rutinas de oración desde la infancia y no tuvieron la intención de revelarse contra sus creencias hasta que algún evento personal o familiar les produjo una crisis. Esta crisis se expresa en las entrevistas como el rechazo a las ideas de Dios, de Bien y Mal, y especialmente a la externalidad trascendente de lo sagrado, que condena al creyente a la aceptación resignada y la pasividad. Frente a esto, el individuo todavía interesado en "conectarse con la dimensión espiritual" comienza una andadura personal en busca de la espiritualidad al estilo del giro subjetivo que describen Heelas y Woodhead, esto es, en contra de la religión al estilo "life-as model". Cada persona va desarrollando este itinerario de una forma heterogénea que se circunscribe a las biografías personales, pero todos coinciden en una secuencia básica común que se repite cada cierto tiempo, mostrando su progresiva incorporación como script conductual del "subjective-life model". En primer lugar se lee o se oye acerca de alguna creencia o práctica. En segundo lugar se toma la decisión (o no) de probarlo o estudiarlo, bien sea convirtiéndose en cliente 0 bien en autodidacta. En ambos casos ello conduce al punto crucial que es el tercer paso, la contrastación: "¿funciona esto para mí?".

Esta sola frase condensa el sentido de toda la revolución espiritual. En cualquier otro momento de la historia religiosa una frase como ésta carecería de sentido, pero en la actualidad son las preguntas acerca de la verdad, la coherencia o la bondad generales, objetivas y exentas, las que quedan atrás. "¿Funciona esto para mí?" supone incorporar a la esfera religiosa un utilitarismo estrictamente individual y relativista en el que la experiencia propia se erige en criterio principal. Cuando la respuesta es negativa, el buscador espiritual vuelve al comienzo y se interesa por otra práctica o doctrina. Cuando la respuesta es positiva, el itinerario continúa hacia alguna forma de disciplinamiento, bien sea el aprendizaje autodidacta o la participación activa en alguna actividad o grupo relacionados con aquello que funciona. Si el individuo (que sigue preguntándose por la eficacia subjetiva de su experiencia) experimenta esa cuarta fase con éxito, quienes desean comprometerse a fondo con la disciplina recién adquirida darán el paso hacia una quinta etapa: la adquisición de un rol estable en el campo espiritual, bien sea como profesional especializado o como cliente (o converso) que practica regularmente con cierto grado de compromiso colectivo.

Como se decía al principio, una de las características de la espiritualidad contemporánea es la pluralidad y heterogeneidad interna de su composición. Un individuo en busca de la espiritualidad puede hacer y rehacer este itinerario cuantas veces quiera. Tal vez toda su vida. $Y$ es frecuente que una misma persona sea especialista en múltiples disciplinas que ha ido explorando progresivamente a medida que se aleja de una religiosidad exterior e institucional y consolida el giro subjetivo de lo sagrado. Sin embargo, ¿por qué un individuo en pos de la espiritualidad individual e individualista se 
convierte en miembro de una organización como Soka Gakkai? Como cabe suponer, porque "funciona" en el fortalecimiento de lo individual. Pero también porque va más allá.

\section{Del self a la membresía: notas sobre poder}

Comparando con su experiencia en múltiples disciplinas alternativas, Nadia (27 años) afirma que "esta práctica es más simple, pero es más completa". Según David (51 años), concienzudo estudioso de la filosofía oriental, "es el camino más corto, la herramienta más rápida" hacia el crecimiento personal y sus frutos en forma de logros, metas cumplidas. El budismo Nichiren ofrece la tradición doctrinal, la vocación social y la plataforma organizativa que no ofrecen la dispersión y el relativismo del patchwork belief y el ambiente holístico, conservando, además, el mismo sentido de poder individual y la misma prioridad de la experiencia subjetiva, modulada ya por el vocabulario de la organización. Como ejemplo, este fragmento de e-mail (Chiara, 34 años).

Sinceramente hay otra cosa que me ha decepcionado. De verdad he rezado con todo mi corazón que vayamos el sábado a Salamanca. No puedo negar que haber recibido un NO ha sido una decepción después de mi Daimoku. Y esta mañana he tenido una larga charla con mi Gohonzon. Y al final le dije (o mejor dicho - a mí misma). "Pues que sepas que yo sigo orando por esta cita. Todos me dicen que con el Gohonzon lo imposible es posible. Pues entonces sigo orando por el sábado". Ya te contaré!

Asimismo, también es posible observar que el individuo es animado a comprometer su poder y sus metas personales con el poder y las metas generales de la Soka Gakkai, y ello en dos sentidos (a veces convergentes): el de la transmisión de la práctica a otras personas (shaku-buku) y el de la búsqueda de la Paz y la felicidad colectiva (Kosen $R u f u)$. Como se aprecia en la convocatoria de esta reunión, realizada por e-mail por la responsable de jóvenes de España:

En marzo cada grupo va a desarrollar un "Foro de Jóvenes por la Paz", para conmemorar el 16 de marzo, día del Kosen-Rufu. Se trata de un encuentro que no es una reunión de diálogo budista sino un espacio de encuentro entre jovenes practicantes del budismo y gente que no practica, en la que se va a hablar de la Paz y los valores sobre los que nos basamos. Se puede decir que los jóvenes de Soka se van a desafiar para "salir a la sociedad".

Así también, el acompañamiento y orientación de unos miembros por otros es un principio general de las relaciones entre los practicantes de este budismo y también la forma principal de control interno de la organización. Aunque el enorme aparato institucional de Soka Gakkai pueda dar una idea diferente, el poder que se ejerce en la comunidad de practicantes de España es difuso y las relaciones de poder tienen el igualitarismo y el pluralismo como principio ideal. Esto provoca algunas paradojas 
significativas. Este es el caso de la omnipresencia del presidente Ikeda en textos, vídeos, discursos, e incluso en la invocación del gongyo. Es común en las reuniones con no practicantes que los practicantes budistas cuenten que este presidencialismo les supuso una contradicción respecto al imperativo de "manifestar la budeidad" individual en los comienzos de su práctica. Frente a ello, sin embargo, se presenta a Daisaku Ikeda como "un ser humano como nosotros" que ha triunfado en su vida gracias precisamente a manifestar la budeidad. Otro tema que se trata de forma parecida, como paradojas de los comienzos, es el relativo a la separación de hombres y mujeres, jóvenes y mayores. Para los miembros más antiguos, por otro lado, una paradoja política más es la que se da en aquellas ocasiones en que alguien con alguna responsabilidad en la organización corrige la conducta privada individual. Estos conflictos son delicados y resulta difícil escribir sobre ellos sin comprometer la confidencialidad, pero al menos un ejemplo sencillo puede resultar ilustrativo. En una ocasión que tuve la oportunidad de comentar con los implicados, una persona publicó fotografías de una reunión en Facebook. Su responsable superior le indicó que esto no era apropiado. Esta persona se defendió argumentando que la organización publica fotografías de sus miembros en sus revistas y entendía su iniciativa como algo semejante, a lo que se le respondió que Facebook presentaba problemas respecto al derecho de protección de datos de los miembros que no se daban en el caso de la revista sin especificar estas condiciones.

A pesar de estas paradojas, uno de los principales atractivos del Soka Gakkai para sus miembros es la posibilidad de trascender la espiritualidad individualista y proyectar su poder hacia la transformación social que predica la Revolución Humana de Daisaku Ikeda (2008). En efecto, una de las características propias y controvertidas del Budismo anti-monástico entre otros budismos es su vocación pública en este sentido. La importancia del Sutra del Loto en esta práctica fundamenta doctrinalmente esto, ya que ofrece la doctrina más popular del budismo Mahayana: la iluminación es un objetivo accesible a todos los seres humanos (y no solo a los santos) en el periodo de una sola vida (Ikeda 2010). Cuando en 1930 Tsunesaburo Makiguchi fundó la Sociedad de los Valores, recuperó las enseñanzas de Nichiren Daishonin precisamente por la importancia que éste daba la transformación social, una transformación social que debía empezar por el individuo como manifestación del Dharma Sublime, y como lugar en que se funda el Valor (Bethel 2000). Esto condujo a los budistas nichiren japoneses a la creación de un partido político (Metraux 2000), aunque en la actualidad Soka Gakkai ha redefinido su labor política como una tarea de pedagogía filosófica a varios niveles: desde la transmisión shaku-buku (hablar de la práctica a otras personas), hasta las conferencias de alto nivel de Daisaku lkeda en la Organización de Naciones Unidas o en el Club de Roma (Díez Hochleitner \& Ikeda 2009). Como parte de esa estructura, los miembros de Soka Gakkai de España no solo aprecian los beneficios personales de la práctica, sino que también se sienten partícipes de un gran movimiento de reforma humanista que busca la paz y la felicidad globales. 


\section{Cuestiones generales e hipótesis en JUego}

La primera idea general a la que conduce este estudio de caso es que las variedades religiosas recogidas en los conceptos "espiritualidad" y "religión", tal y como se proponen en la Sociología de la Espiritualidad, no se dan como alternativas opuestas, incompatibles o excluyentes, sino que guardan una relación dinámica que dibuja otro panorama del cambio religioso. Cuando Paul Heelas, Linda Woodhead, Steve Bruce, Danièle HervieuLeger y otros han puesto la atención sobre estas cuestiones, han intentado trazar una teoría que permita dar cuenta al mismo tiempo del declive de la religión eclesial y del aumento de la espiritualidad subjetiva. Sin embargo, a través de este caso podemos ver que la espiritualidad individual se incrusta de hecho en un extenso aparato institucional, formando parte tanto del fundamento ritual y práctico (cantar daimoku para "conseguir más cosas") como del doctrinal ("manifestar la budeidad" como síntesis del Sutra del Loto). Desde este punto de vista, por tanto, la reconstitución de las formas colectivas de religiosidad es posible e incluso deseada por muchos buscadores espirituales. Esto no significa que el concepto clave propuesto por la Sociología de la Espiritualidad sea inútil. Antes al contrario, permite apreciar el modo en que los actores sociales expresan el cambio religioso producido en su interior y en su exterior, en su campo religioso de referencia. En este sentido, si bien debemos trabajar sobre la dicotomía entre religión y espiritualidad tal y como se vive y presenta en los discursos de los actores sociales, asumir este mismo esquema para la explicación general de las prácticas religiosas oscurece la dimensión institucional y política de la nueva espiritualidad, tanto por lo que respecta al desarrollo organizativo de la experiencia espiritual, como por lo que respecta a las relaciones de poder internas, la reproducción de diferencias de género y a la ideología de cambio global que pueden acompañar al subjetivismo religioso.

Otra de las cuestiones generales que podemos extraer de este estudio de caso guarda relación con la espiritualidad como herramienta de aprendizaje del self y no sólo como su expresión final. Como hemos visto, si una de las dimensiones más significativas en el cambio de cultura religiosa tiene que ver con el desplazamiento de la autoridad desde el exterior (Dios, Iglesia, comunidad) hacia el interior (en este caso "la budeidad"), esta transformación no se produce solo como efecto inmediato de los cambios sociales e históricos en la familia, la educación o el trabajo. Una perspectiva sobre las trayectorias personales permite apreciar que la nueva cultura religiosa consiste en un aprendizaje pautado, en la adquisición de una nueva disciplina religiosa y no solo en un consumo anárquico de creencias y prácticas. Ante el inmenso repertorio del "ambiente holístico" el individuo con inquietudes religiosas debe aprender un nuevo modo de gestión y validación del conocimiento religioso basado en la experiencia estrictamente personal. Para aquellos educados en el seno de familias católicas, y especialmente para las mujeres, ello implica un proceso de aislamiento del self a través de la experimentación subjetiva, tras el cual la subjetividad queda incorporada a los esquemas cognitivos y guiones conductuales de la nueva cultura religiosa como elemento central. Pero al mismo tiempo que se dan el aprendizaje de la subjetividad y la articulación de variedades religiosas 
cabe suponer que este aprendizaje no es el mismo ni tiene el mismo sentido en campos religiosos tradicionalmente plurales que en campos religiosos basados en el monopolio eclesial, como es el caso de las sociedades culturalmente católicas del sur de Europa.

Sorprendentemente, los estudios sobre Soka Gakkai en el Reino Unido, pioneros en Europa, encuentran significativa la escasez de conversos católicos (Wilson 1994), sin embargo, el país europeo con mayor número de budistas nichiren es Italia (Macioti 2000) de donde proceden, además, un buen número de los miembros de Soka Gakkai residentes en España. Esto parece sugerir que estamos ante alguna pauta de transformación del campo religioso postcatólico relacionada con el budismo. Como se ha mencionado antes, la forma en que estos budistas imaginan "la religión" (como life-as model) no coincide con el "dominio congregacional" propuesto por Heelas y Woodhead, ya que en el caso del campo religioso de España otras adscripciones religiosas (cristianas o no) son minoritarias y la mayoría de las veces lejanas en la red social del individuo. En este dominio católico, las crisis espirituales difícilmente desembocan en el contacto inmediato con otra comunidad de creyentes sino que pasan antes por búsquedas solitarias de alternativas espirituales que tiene el efecto de incorporar un principio individualista poco presente en el catolicismo (Cornejo-Valle 2008). Las investigaciones empíricas sobre el budismo Nichiren hasta ahora han estudiado los antecedentes de los budistas solo teniendo en cuenta su adscripción congregacional, y no han descrito itinerarios espirituales significativos. Sin embargo, al menos desde España parece posible confirmar la hipótesis según la cual las trayectorias de búsqueda espiritual son un elemento fundamental en la transición desde el catolicismo hasta el budismo.

\section{REFERENCIAS BibLIOGRÁFICAS}

Baumann, M. 2002. "Buddhism in Europe. Past, present, prospects". Pp. 85-105 en Westward Dharma:Buddhism beyond Asia, editado por Martin Baumann y Charles S. Prebish. Berkeley: University of California Press.

Beck, U. 2009. El Dios personal. La individualización de la religión y el espiritu del cosmopolitismo. Barcelona: Paidós.

Bethel, D. 2000. "The legacy of Tsunesaburo Makiguchi: value-crating education and global citizenship". Pp. 42-66 en Global Citizens. The Soka Gakkai Movement in the Wolrd, editado por D. Machacek y B. Wilson. Oxford: Oxford University Press.

Bruce, S. 1996. Religion in the modern World. From Cathedrals to Cults. Oxford: Oxford University Press.

Cornejo Valle, M. 2008. La construcción antropológica de la religión. Etnografía de una localidad manchega. Madrid: Ministerio de Cultura.

Díez de Velasco, F. 2009. "La visibilización del budismo en España". Pp. 154-259 en Budismo y cristianismo en diálogo, editado por M. M. Pintos de Cea-Naharro. Madrid: Universidad Carlos III de Madrid. 
Dillon, M. and P. Wink. 2003. "Religiousness and Spirituality: Trajectories and Vital Involvement in Late". Pp. 179-189 en The Handbook of the Sociology of Religion, editado por M. Dillon. Cambridge: Cambridge University Press.

Dobbelaere, K. 2000. "Toward a pillar organization?". Pp. 233-37 en Global Citizens. The Soka Gakkai Movement in the Wolrd, editado por D. Machacek y B. Wilson. Oxford: Oxford University Press.

Flanagan, K. and P. C. Jupp. 2007. A Sociology of Spirituality. Alderchot: Ashgate.

Forman, R. K. C. 2004. Grassroots Spirituality: What it is, Why it is Here, Where it is Going. Exeter: Imprints Academic.

Giordan, G. 2007. "Spirituality: from a religious concept to a sociological theory". Pp. 161-80 en A Sociology of Spirituality, edited by K. Jupp and P. C. Flanagan. Aldershot: Ashgate.

Griera, M. M. y F. Urgel. 2002. Consumiendo religión. Nuevas formas de espiritualidad entre la población juvenil. Barcelona: Fundación La Caixa.

Hammond, P. and D. Machacek. 1999. Soka Gakkai in America. Accomodation and Conversion. Oxford: Oxford Univeristy Press.

Heelas, P. 2003. The New Age Movement. The Celebration of the Self and the Sacralization of Modernity. Oxford: Blackwell.

Heelas, P. and L. Woodhead et al. 2008. The Spiritual Revolution. Why Religion is Giving Way to Spirituality. Oxford: Balckwell.

Hervieu-Leger, D. 2003. "Individualism, the validaton of faith and the social nature of religion in modernity". Pp. 161-75 en The Blackwell Companion to Sociology of Religion, edited by R. K. Fenn. Oxford: Blackwell.

Ikeda, D. 1999. El nuevo humanismo. México: Fondo de Cultura Económica.

Ikeda, D. 2008. La nueva revolución humana. Madrid: Civilización Global.

Ikeda, D. 2010. El logro de la budeidad en esta existencia. Madrid: Civilización Global.

Lofland, J., R. Stark, 1965. "Becoming a world-saver: a theory of conversion from a deviant perspective." American Sociological Review 30 Pp. 862-75.

López García, B., A. Ramírez Fernández, E. Herrero Galiano, S. Kirhlani, M. Tello Weiss. 2007. Arraigados: Minorias religiosas en la Comunidad de Madrid. Madrid: Icaria.

Luckmann, T. 1973. La religión invisible. El problema de la religión en la sociedad moderna. Salamanca: Sígueme.

Macioti, M. I. 2000. "Buddhism in action: case studies from Italy". Pp.375-401 en Global Citizens. The Soka Gakkai Movement in the Wolrd, editado por D. Machacek y B. Wison. Oxford: Oxford University Press. 
McGuire, M. 2008. "Towards a sociology of spirituality. Individual religion in social/historical context". Pp. 215-32 en The Centrality of Religion in Social Life: Essays in Honour of James A. Beckford, editado por E. Barker. Aldershot: Ashgate.

Metraux, D. 2000. "The changing role of Komeito in Japanese politics". Pp. 128-52 en Global Citizens. The Soka Gakkai Movement in the Wolrd, editado por D. Machacek y B. Wison. Oxford: Oxford University Press.

Roof, W. C. 2003. "Religion and spirituality: toward an integrated analysis". Pp. 137-48 en The Handbook of the Sociology of Religion, editado por M. Dillon. Cambridge: Cambridge University Press.

Seager, R. H. 2006. Encountering the Dharma. Daisaku Ikeda, Soka Gakkai and the Globalization of Buddhist Humanism. Berkeley: University of California Press.

Sennett, C. 1998. The Corrosion of Character: The personal Consequences of Work in Modern Capitalism. New York: Norton cop.

Tacey, D. J. 2004. The Spirituality Revolution: the Emergence of Contemporary Spirituality. Hove: Brunner-Routledge.

Taylor, C. 1992. The Sources of the Self: the Making of Modern Identity. Cambridge: Cambridge University Press.

Vallverdú, J. 1999. "Conversión, compromiso y construcción de la identidad en el movimiento Hare Krishna." Alteridades 9:18. Pp. 57-70.

Wilson, B. and K. Dobbelaere. 1994. A Time to Chant: the Soka Gakkai Buddhist in Britain. Oxford: Oxford University Press.

Wilson, B. and D. Machacek. 2000. Global Citizens. The Soka Gakkai Buddhist Movement. Oxford: Oxford University Press.

Wood, M. 2009. "The nonformative elements of religious life: Questioning the Sociology of Spirituality Paradigm." Social Compass 56: 237-48.

Woodhead, L. 2007. "Why so many women in holistic spirituality? A puzzle revisited". Pp. 115-25 en A Sociology of Spirituality, edited by K, Jupp and P. C. Flanagan. Aldershot: Ashgate.

Woodhead, L. and P. Heelas. 2000. Religion in Modern Times: an Interpretative Anthology. Oxford: Blackwell.

Wuthnow, R. 2003. "Spirituality and spiritual practice". Pp. 306-18 en The Blackwell Companion to Sociology of Religion, edited by R. K. Fenn. Oxford: Blackwell.

MÓNICA CORNEJO es Profesora de la Universidad Complutense de Madrid, Doctora en Antropología Social, Premio Nacional de Investigación Cultural Marqués de Lozoya 2007, especialista en Religión y Antropología Cognitivo-Simbólica. Autora del libro La construcción antropológica de la religión (2008, Ministerio de Cultura).

RECIBIDO: $08 / 09 / 2010$

ACEPTADO: 14/02/2011 